\title{
Tobacco Hatch-Slack Enzymes are Involved in Both, Abiotic and Biotic Stress Response
}

\section{Veronika Hýskova* and Helena Ryslava}

Department of Biochemistry, Charles University in Prague, Czech Republic

While the photosynthetic function of enzymes forming the HatchSlack cycle in some C4 and CAM plants is well known, the possible roles of their non-photosynthetic counterparts, present in all plants, are still studied. The photosynthetic enzymes evolved approximately 85-65 millions years ago as a part of plant strategy how to increase $\mathrm{CO}_{2}$ concentration for the Calvin cycle and thus decrease photorespiration $[1,2]$. The Hatch-Slack cycle of NADP-malic enzyme type comprises of four enzymes; the first one, phosphoenolpyruvate carboxylase (PEPC, EC 4.1.1.31), enables $\mathrm{CO}_{2}$ pre-fixation to four-carbon compound oxaloacetate (OAA), which is further reduced by NADPmalate dehydrogenase (NADP-MDH, EC 1.1.1.82) to L-malate. This compound is transported to the chloroplasts of bundle sheath cells, the place where the Calvin cycle operates, to be decarboxylated by NADP-malic enzyme (NADP-ME, 1.1.1.40). The last enzyme pyruvate, phosphate dikinase (PPDK, EC 2.7.9.1) is responsible for the regeneration of the primary acceptor phosphoenolpyruvate $[2,3]$. In the plants exposed to arid conditions with high temperatures and high light intensities, the presence of this additional photosynthetic pathway is advantageous due to the reduction of transpiration and photorespiration, even at the cost of ATP.

Various functions were suggested for non-photosynthetic isoforms of these enzymes. The role of PEPC is supposed to be anaplerotic; the intermediates of the citric acid cycle can be replenished by the production of OAA and L-malate, respectively. Moreover, the PEPC product oxaloacetate can serve as a carbon skeleton source for nitrogen assimilation and as amino acids biosynthesis precursor. Similarly, the precursor 2-oxoglutarate can be formed from OAA by the citric acid cycle. Thus, this enzyme can connect the metabolism of saccharides (substrate phosphoenolpyruvate as the metabolite of glycolysis) with the metabolism of nitrogen and amino acids [4]. Nitrogen metabolism, especially during leaf senescence is also influenced by PPDK. This enzyme can substantially accelerate nitrogen mobilization from leaves, and thereby increase the weight of seeds [5]. PEPC and NADP$\mathrm{ME}$ together participate in the regulation of $\mathrm{pH}$ [6]. NADP-ME is probably involved in fruit ripening [7]. In addition, PEPC with NAD$\mathrm{MDH}$ are involved in the reoxidation of NADH during the process of malate fermentation [6]. An important function of NADP-ME is the production of reducing equivalent NADPH, which serves as a coenzyme in the biosynthetic processes including the biosynthesis of defense compounds (flavonoids, lignins, mannitol, fatty acids), as a coenzyme of antioxidant enzymes (e.g. glutathion reductase EC 1.8.1.7; monodehydroascorbate reductase EC 1.6.5.4), and as a substrate for plasma membrane NADPH-oxidase generating signal molecules of stress-reactive oxygen species [8]. In the case of need, NADPH can be oxidized by the respiratory chain using specific mitochondrial NADPH-dehydrogenase to form ATP [7]. Other NADP-ME products are utilizable, too; pyruvate as a substrate for the respiration or biosyntheses and $\mathrm{CO}_{2}$ can be provided to the photosynthesis in some tissues associated with reproductive organs [7]. PPDK also catalyzes the reversible reaction in the direction of pyruvate, ATP, and Pi formation and thus this enzyme can bypass the reaction catalyzed by pyruvate kinase and serve as a glycolytic enzyme $[9,10]$.
In addition to a lot of various and useful functions of nonphotosynthetic PEPC, NADP-ME, and PPDK, these enzymes are together involved in stress. The activities of the Hatch-Slack nonphotosynthetic enzymes from tobacco (Nicotiana tabacum L., cv. Petit Havana SR1), as a model of $\mathrm{C}_{3}$ plants, were increased in the response to both biotic stress caused by Potato virus A and Potato virus $\mathrm{Y}$ (strain NTN and $\mathrm{O}$ ) and abiotic stress caused by drought [10-13]. Some consequences of these types of stress are similar, e.g. growth reduction, damage of leaf surface, stomatal closure, repression of net photosynthesis rate, and oxidative stress. As well some plant defense strategies against biotic and abiotic stress are analogous (such as the activation of respiration and antioxidant system, synthesis of protective compounds), while e.g. the accumulation of osmotically active compounds is characteristic for drought stress. Under the conditions of all types of stress production of NADPH by NADP-ME, replenishing of citric acid cycle with metabolites by PEPC and NADP$\mathrm{ME}$, and regeneration of PEP by PPDK would be useful. However, if PEPC, NADP-ME, PPDK and NAD-malate dehydrogenase (EC 1.1.1.37), whose activity is high in plants, can form a cycle in $\mathrm{C}_{3}$ plants, is not known. Even though this hypothetical cycle consumes ATP, it converts NADH to NADPH and produces $\mathrm{CO}_{2}$ available for Calvin cycle [4].

The regulation of the above mentioned enzymes is also interesting [13-17]. While the tobacco leaves NADP-ME was probably synthesized de novo during a viral infection and drought stress, the regulation of PEPC under these conditions seems to be affected by phosphorylation, which increases the enzyme activity and sensitivity to the activator $\mathrm{D}$-glucose-6-phosphate $[10,12,13]$. In general, the reversible regulation by phosphorylation of both, PEPC and PPDK, is mediated via protein kinases. PEPC kinase is the smallest known kinase, which caused phosphorylation of the conserved serine near the N-terminus of PEPC [14], while PPDK is regulated by phosphorylation of the threonine residue using specific bifunctional regulatory protein [15]. This regulatory protein is very unusual, because it can act as a kinase as well as a reversible dephosphorylating enzyme. Moreover, the PPDK regulatory protein uses ADP versus ATP as its phosphoryl donor and utilizes a phosphorolytic mechanism of dephosphorylation [15]. Different isoforms of NADP-ME from tobacco leaves were involved in the stress response; increased mRNA transcription of the cytosolic

*Corresponding author: Veronika Hyskova, Department of Biochemistry, Charles University in Prague, Hlavova, Czech Republic, Tel: 420221951282; E-mail: veronika.hyskova@natur.cuni.cz

Received November 30, 2013; Accepted December 03, 2013; Published December 05, 2013

Citation: Hýskova V, Ryslava H (2013) Tobacco Hatch-Slack Enzymes are Involved in Both, Abiotic and Biotic Stress Response. Biochem Anal Biochem 2: e145. doi: 10.4172/2161-1009.1000e145

Copyright: (C) 2013 Hýskova V, et al. This is an open-access article distributed under the terms of the Creative Commons Attribution License, which permits unrestricted use, distribution, and reproduction in any medium, provided the original author and source are credited. 
Citation: Hýskova V, Ryslava H (2013) Tobacco Hatch-Slack Enzymes are Involved in Both, Abiotic and Biotic Stress Response. Biochem Anal Biochem 2: e145. doi: 10.4172/2161-1009.1000e145

Page 2 of 2

and chloroplastic isoform was found in the case of a viral infection and drought, respectively $[10,12]$. Since the chloroplasts play a crucial role in the initiation of response to drought and the abscisic acid signaling, it is possible that chloroplastic NADP-ME participates in this system $[10,18]$.

The individual non-photosynthetic Hatch-Slack enzymes were found to be involved in other stressor-plant interactions, too. For example, PEPC is involved in biosynthesis of organic acids in the conditions of phosphate and iron deficiency and aluminium toxicity. PEPC is also related to chilling stress, where it is supposed to synthesize L-malate (in a cooperation with NAD-malate dehydrogenase), which serves as an osmolyte and as an additional sink for the carbon assimilation and NADPH $[4,19]$. Particular isoforms were found to be a part of the response of various plants to stresses (e.g. cold, submergence, osmotic stress, nutrient deficiency stress, ozone stress etc). All incidences of the response of individual enzymes are summarized in our review [4]. However, there are only few publications, in which all non-photosynthetic Hatch-Slack enzymes are studied in a connection with stress together. It would be interesting to know, if these enzymes cooperate during stress response and which plant-stressor systems use the non-photosynthetic isoforms of Hatch-Slack enzymes as a part of a defense strategy. Some plant species probably employed different metabolic pathways as was concluded from our experiments with Nicotiana benthamiana plants and biotic stress [20].

\section{References}

1. Ku MSB, Kano-Murakami Y, Matsuoka M (1996) Evolution and expression of C4 photosynthesis genes. Plant Physiol 111: 949-957.

2. Sage RF (2004) The evolution of C4 photosynthesis. New Phytol 161: 341-370

3. Ryslava H, Doubnerova V (2010) Enzymes of the Hatch-Slack cycle in C3 plants. Chem Pap104: 1175-1180.

4. Doubnerová $V$, Ryšlavá $H$ (2011) What can enzymes of $C_{4}$ photosynthesis do for $\mathrm{C}_{3}$ plants under stress? Plant Sci 180: 575-583.

5. Taylor L, Nunes-Nesi A, Parsley K, Leiss A, Leach G, et al. (2010) Cytosolic pyruvate,orthophosphate dikinase functions in nitrogen remobilization during leaf senescence and limits individual seed growth and nitrogen content. Plant J 62: 641-652.

6. Latzko E, Kelly GJ (1983) The many-faceted function of phosphoenolpyruvate carboxylase in C-3 plants. Physiol Veg 21: 805-815.
7. Edwards GE, Andreo CS (1992) NADP-malic enzyme from plants Phytochemistry 31: 1845-1857.

8. Doubnerova V, Ryslava H (2012) NADP-dependent enzymes and abiotic stress. In, Haryana, N, Punj, S. Editors, Abiotic Stress New Research. Nova Science Publishers.

9. Plaxton WC, Tran HT (2011) Metabolic adaptations of phosphate-starved plants. Plant Physiol 156: 1006-1015.

10. Hyskova Doubnerova V, Miedzinska L, Dobra J, Vankova R, Ryslava H (2014) Phosphoenolpyruvate carboxylase, NADP-malic enzyme, and pyruvate, phosphate dikinase are involved in the acclimation of Nicotiana tabacum L. to drought stress. J Plant Physiol 171: 19-25.

11. Ryslava H, Muller K, Semoradova S, Synkova H, Cerovska N (2003) Photosynthesis and activity of phosphoenolpyruvate carboxylase in Nicotiana tabacum $L$. leaves infected by Potato virus $A$ and Potato virus $Y$. Photosynthetica 41: 357-363.

12. Doubnerova V, Muller K, Cerovska N, Synkova H, Spoustova P, et al. (2009) Effect of Potato Virus Y on the NADP-malic enzyme from Nicotiana tabacum L. mRNA, expressed protein and activity. Int J Mol Sci 10: 3583-3598.

13. Muller K, Doubnerova V, Synkova H, Cerovska N, Ryslava H (2009) Regulation of phosphoenolpyruvate carboxylase in PVYNTN-infected tobacco plants. Biol Chem 390: 245-251.

14. Chollet R, Vidal J, O' Leary MH (1996) Phosphoenolpyruvate carboxylase: a ubiquitous, highly regulated enzyme in plants. Annu Rev Plant Physiol Plant Mol Biol: 47: 273-298.

15. Chastain CJ, Xu W, Parsley K, Sarath G, et al. (2008) The pyruvate orthophosphate dikinase regulatory proteins of Arabidopsis possess a novel, unprecedented Ser/Thr protein kinase primary structure. Plant J 53: 854-863.

16. Cerný M, Doubnerová V, Müller K, Ryšlavá H (2010) Characterization of phosphoenolpyruvate carboxylase from mature maize seeds: Properties of phosphorylated and dephosphorylated forms. Biochimie 92: 1362-1370.

17. Doubnerova V, Potuckova L, Muller K, Ryslava H (2009) The regulation and catalytic mechanism of the NADP-malic enzyme from tobacco leaves. J Serb Chem Soc 74: 893-906.

18. Mochizuki N, Brusslan JA, Larkin R, Nagatani A, Chory J (2001) Arabidopsis genomes uncoupled 5 (GUN5) mutant reveals the involvement of Mg-chelatase $\mathrm{H}$ subunit in plastid-to-nucleus signal transduction. Proc Natl Acad Sci U S A 98: 2053-2058.

19. Crecelius F, Streb P, Feierabend J (2003) Malate metabolism and reactions of oxidoreduction in cold-hardened winter rye (Secale cereale L.) leaves. J Exp Bot: 54, 1075-1083.

20. Doubnerová V, Jirásková A, Janosková M, Müller K, Bat'ková $P$, et al. (2007) The activity and isoforms of NADP-malic enzyme in Nicotiana benthamiana plants under biotic stress. Gen Physiol Biophys 26: 281-289. 